the relationship between the state, law, and indigenous people.

Andrew Parnaby,

Cape Breton University

\title{
David Frank and Nicole Lang, Labour Landmarks in New Brunswick (Canadian Committee on Labour History, 2010).
}

Labour Landmarks in New Brunswick explores a fascinating but little known aspect of New Brunswick's cultural heritage - the tradition of commemorating the sacrifices and contributions of the province's workers through the creation of labour landmarks. (10)

Crafted by award winning labour historians David Frank and Nicole Lang, with a skilled team of assistants and supporters, it is the most recent offering of Labour History in New Brunswick (lhtnb.ca), a community-university research alliance devoted to fostering an informed public memory related to the history of work in the province.

The authors explain that their study was inspired by the work of Archie Green who, in the 1950s, first began to draw attention to "laborlore" and other working class traditions that typically went unnoticed by historians and folklorists. The present study is limited to one such form of expression - a selection of markers that commemorate the experiences of work and workers in $20^{\text {th }}$ century New Brunswick. The book reads like a fireside chat, traveling across the province, monument by monument, telling the story of how lives were lived, how lives were lost, and how communities came together to ensure that their history would not be forgotten.

Presented in ten brief chapters, in French and in English, Labour Landmarks discusses memorials found in both public and private places, beginning with those erected by families, by unions, and by other workers' organizations. It goes on to consider markers that commemorate the history of work and workers in the major high-risk sectors of the province's traditional economy, including firefighters and coal miners, railway workers and fishermen, mill and forestry workers. A separate chapter examines the Labour movement's "invented tradition" of the April 28 "Day of Mourning" (67) and efforts to raise awareness around the issues of workplace safety and the right to refuse unsafe work. (73)

The book includes 47 photographs of labour markers and of people gathered at these sites for memorial ceremonies (62). These images are placed throughout the book and are interpreted within the text, with photo credits grouped together at the back, following a section of 72 explanatory endnotes. The book concludes with a map and a list of 50 labour landmarks in the 
province. No index is provided.

It is interesting to discover instances where New Brunswick's working women and men have created their own labour landmarks by using their tombstones to make a personal statement about what was significant in their lives, including their work. Symbols of the deceased's working life may be found carved into many of the tombstones, like etchings of fishing boats or miners' tools. Of particular interest are those that commemorate domestic work. Like traditional historical writing, labour landmarks seldom recognize the role of women and domestic work is virtually overlooked, so it is touching to find the cooking, cleaning and homemaking chores that comprised so much of a woman's life honoured by her family on her tombstone.

While some markers serve as memorials to the economic importance of an industry, others honour the workers in these industries. They also may serve as a as a testament to the known risks and unexpected hazards workers face daily, commemorate how workers suffered and sometimes died as a result of adverse workplace conditions, and reveal the lack of regulations and legislation to protect workers. These monuments provide insights into the development of workplace safety legislation and the struggle for workers compensation, restrictions controlling child labour, and controls over hours of work.

Labour markers can create a site where private visits can occur, where a community can gather to remember, and where present and future generations can be warned about the dangers of work. Such places may serve as a catalyst for change and lead to action. The authors contrast a plaque that celebrates the economic importance of coal mining to another, smaller, one that commemorates five individuals who lost their lives in a mining accident. This marker goes on to tell the story of the fight that followed the tragedy for workers' compensation and union recognition to secure safer working conditions.

From simple crosses to major works of public art, the authors explain, these markers reflect an unofficial public culture that results from local initiatives and support. While some are official heritage plaques installed by various levels of government, they did not originate as efforts to promote tourism or to commercialize the province's culture. Many are the product of unions, of church groups, philanthropic organizations, and working women and men themselves. In some cases, they represent contested terrain and contested memory. Together, they reflect a desire to mark the place of workers in the community, the economy and the province.

The authors point to the important role of community groups in saving local heritage buildings from demolition, ensuring their preservation by repurposing them to serve as heritage centres like the McAdam train station. (45) Within the confines of this study, however, they have not attempted to investigate such elements in the built heritage or to explore what museums and galleries may have to offer concerning labour history. 
They warn us, though, that the province's industrial heritage landscape, like the physical remains of the once mighty industries of mining and the railroad, has largely disappeared and is at risk of being lost to public memory. They advise that labour activists and heritage preservationists need to work together to promote an informed public memory of the contributions of working people to society. (91)

Sharon Reilly

The Manitoba Museum, Winnipeg

\section{Axel Fair-Schulz, Loyal Subversion: East Germany and its Bildbungsbürgerlich Marxist Intellectuals, Berlin: Trafo Wissenschaftsverlag, 2009.}

It is all too common to see an individual's relations with ideologies and regimes in simplistic terms. This is even more the case when dealing with one of the many sundry "evil empires" that people in the west have heard about in the past hundred years. Thus it is all the more gratifying to read a work as nuanced and sophisticated as Axel Fair-Schulz and his Loyal Subversion: East Germany and its Bildungsbürgerlich Marxist Intellectuals.

In his work, Axel Fair-Schultz goes beyond the conventional stereotypes that so frequently plague the history of German Democratic Republic (DDR). Rather than merely painting a world of loyal regime toadies and noble, if fear full, dissidents, Fair-Schultz examines a much neglected strata. That is those middle class intellectuals who never forsake their belief in socialism, or the hope that the DDR could make strides in that direction. Yet while remaining to this vision, they subverted and subtlety fought against the dogmatism and undemocratic practices of the leaders of East Germany. As the author noted he focused on" the dynamics of this select group of intellectuals' conformity, accommodation, and - albeit limited - dissent with the context of socialist East Germany (1949-1990).” (12)

Admittedly small in number, Fair-Schultz makes a persuasive case that they had a much greater impact than one would first suspect. By doing case studies of three of the most important of these "loyal subversives" - Jürgen Kuczynski (Economic Historian), Hermann Budzislawski (Journalist), and Stephen Hermlin (writer) - this book makes a powerful case that knowledge of the influence of these men is vital if one is to understand the DDR and her history in all its complexity. What emerges clearly, and surprisingly, is that these men despite their at times "Stalinization," managed to "disentangle their Marxist utopianism from the realities of the Soviet bloc, becoming early and effective critics of the deformation of their ideals." (344) 